\title{
Spatial and temporal structure of predator-prey relationships in the Celtic Sea fish community
}

\author{
V. M. Trenkel ${ }^{1, *}$, J. K. Pinnegar ${ }^{2}$, W. A. Dawson ${ }^{2}$, M. H. du Buit ${ }^{3}$, A. N. Tidd ${ }^{2}$ \\ ${ }^{1}$ IFREMER, Rue de l'Ile d'Yeu, BP 21105, 44311 Nantes cedex 3, France \\ ${ }^{2}$ CEFAS, Lowestoft Fisheries Laboratory, Lowestoft NR33 0HT, UK \\ ${ }^{3}$ CNRS, Collège de France, Laboratoire de Biologie Marine, 29110 Concarneau, France
}

\begin{abstract}
The spatial and temporal structure of predator-prey relationships in the Celtic Sea was investigated for 4 commercially important predator species (cod Gadus morhua, hake Merluccius merluccius, megrim Lepidorhombus whiffiagonis, and whiting Merlangius merlangus) using stomachcontent and bottom-trawl survey data for the period 1982 to 1995. Blue whiting Micromesistius poutassou were consumed more often during the summer months, whereas mackerel Scomber scombrus and Trisopterus spp. (poor cod T. minutus, Norway pout T. esmarkii, and bib T. luscus) were found more often in predator stomachs during the winter half-year. On a spatial scale, blue whiting was consumed over the shelf edge, in accordance with their higher densities in the environment, while mackerel, horse mackerel Trachurus trachurus and Trisopterus spp. were eaten more often on the continental shelf, again in agreement with their depth-related density-distribution patterns. The spatial distribution of whiting closely matched that of a key prey, Trisopterus spp. This might indicate an 'aggregative response' by the predator. The results of this study suggest spatial and seasonal prey-switching behaviour by cod, hake and whiting. Overall, the Celtic Sea fish community is characterised by opportunistic predators and general independence between predator and prey distributions. Interspecific predator interactions are reduced by size-, space- and time-dependent feeding behaviours.
\end{abstract}

KEY WORDS: Diet - Stomach contents · Preference - Celtic Sea - Season - Spatial distribution - Resale or republication not permitted without written consent of the publisher

\section{INTRODUCTION}

Although a considerable amount is known about who eats whom in marine systems, much less is understood about the dynamics, and specifically how diets of marine consumers relate to changes in the abundance of their prey (Greenstreet et al. 1998). Many marine fishes are opportunistic predators and readily switch feeding preferences in space as well as in time, either on a seasonal (Greenstreet et al. 1998) or interannual (Jennings \& Kaiser 1998, Link \& Garrison 2002) basis. Consequently, marine ecosystems are characterised by highly connected food webs, but a multitude of weak predatorprey linkages (Garrison \& Link 2000, Link 2002).

Recent simulation studies (e.g. Drossel et al. 2004) have demonstrated that it is this 'switching' behaviour, between a small portfolio of key prey-types, which cre- ates long-term stability in complex systems. Other theoretical studies (e.g. Murdoch 2002) have shown that for generalist predators, long-term population dynamics are independent of the availability of particular prey cycles. Consequently it has been argued that single-species models might be justified for many generalist predators. Using a predator-prey model based on 2 fish species (differential equations; partially coupled predator-prey interactions) with alternative food and red noise, Spencer \& Collie (1995) found that the inclusion of alternative food adds stability to predator abundance at low prey levels, supporting the argument that generalist predators possess population dynamics independent of any particular prey species.

Predators are able to respond to spatial and temporal changes in prey availability by altering their consumption rate (functional response), their population growth 
rate (numerical response) or their spatial distribution (aggregative response). The aggregative response describes the relationship between the spatial distribution of the prey and that of its predator. The requirement to maximise food or energy intake will theoretically lead to a redistribution of predators to more profitable 'patches' containing higher prey densities (see Hassell \& May 1974, Anderson 2001). Assuming that predator behaviour is well described by the 'ideal free distribution' theory (see review by Van der Meer \& Ens 1997), then the assumed form of the functional response, in particular the assumptions made regarding predator interference, will determine whether or not there is also an aggregative response. In practice, however, while it is possible to determine the overlap in the spatial and temporal distributions of predators and preys, it is often difficult to untangle the conflicting explanations for the observed geographic distribution patterns. Predator and prey distributions might overlap simply because of common habitat preferences (substrate, temperature etc.) rather than necessarily having anything to do with predators actively seeking out a particular prey.

Variability in prey preferences on a spatially and temporarily resolved level have been studied by modelling prey occurrence in predator stomachs as a function of environmental variables (geographic location, depth and temperature) and predator characteristics (e.g. length). Generalised linear and generalised additive models offer a flexible modelling framework; Stefánsson \& Pálsson (1997) used it for studying shrimp and capelin occurrence in Icelandic cod stomachs, and this is also the approach we have adopted here.

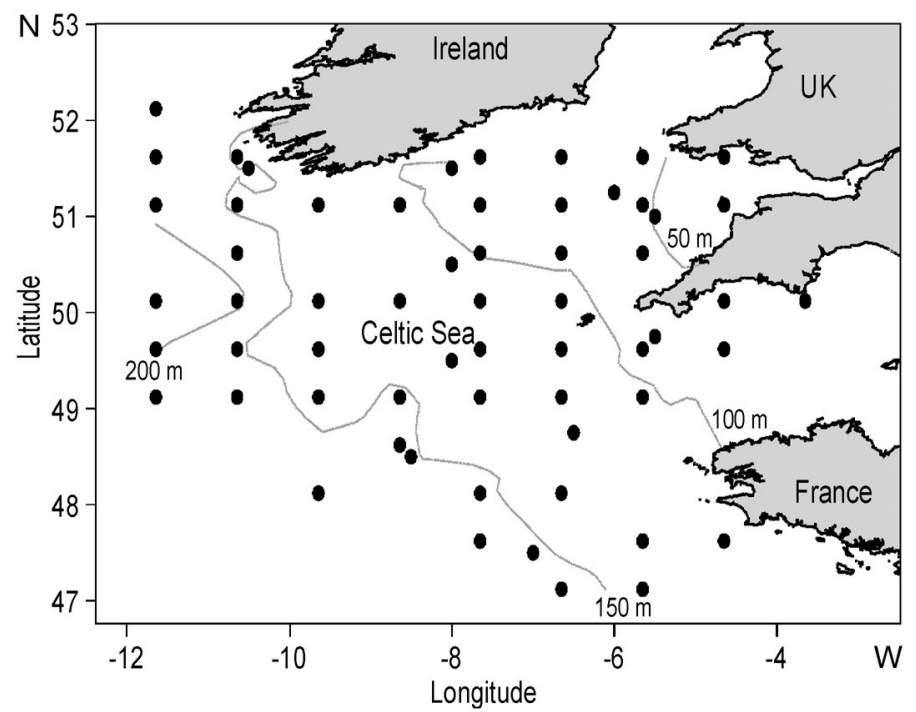

Fig. 1. Study area and stomach-data locations (•, all years combined). For French stomach samples, locations correspond to centre of sampled ICES subdivisions
The Celtic Sea is an area of continental shelf bordered by Ireland in the north, the UK in the east, and the Bay of Biscay $\left(47^{\circ} \mathrm{N}\right.$ latitude line) in the south (Fig. 1). In terms of its fish assemblages it is distinct from the Irish Sea, the English Channel and the Bay of Biscay. For example, sandeel Ammodytes marinus, an important prey species both in the neighbouring Irish Sea (Seyhan \& Grove 1998) and the nearby southern North Sea (de Panafieu 1986, Pedersen 1999) are practically absent from the Celtic Sea. The Celtic Sea fish community consists of many generalist predators.

In a previous paper, we studied aggregated predatorprey relationships for selected predators in the Celtic Sea, using stomach-content data (Pinnegar et al. 2003). The choice of predators was governed by data availability: cod Gadus morhua, hake Merluccius merluccius, megrim Lepidorhombus whiffiagonis, saithe Pollachius virens and whiting Merlangius merlangus. The dominant prey species were the same for the 5 predators: argentines Argentina spp., dragonets Callionymus spp., clupeoids Sardina pilchardus, Sprattus sprattus, Clupea harengus, blue whiting Micromesistius poutassou, mackerel Scomber scombrus, horse mackerel Trachurus trachurus and Trisopterus spp. (poor cod T. minutus, Norway pout T. esmarkii, and bib T. luscus). Certain prey species were grouped on the family level as it was impossible to distinguish species in the stomachs. In that study (Pinnegar et al. 2003) we looked at the relationship between the average proportion of the prey items in predator stomachs and prey stock abundance as well as the average proportion of a given prey in trawl survey data in a given year. The average occurrence of blue whiting in the stomachs of hake and megrim was positively related to blue whiting stock abundance, as determined from International Council for the Exploration of the Sea (ICES) stock assessments. Furthermore, the average proportion of blue whiting in cod and hake stomachs was also positively related to the average proportion of blue whiting in scientific trawl surveys. There was weak evidence for horse mackerel being consumed more often by hake when more abundant in scientific trawl surveys. Mackerel stock abundance was unrelated to the mackerel proportion in predator stomachs. Using Chesson's standard forage ratio, we found that cod and megrim had a preference for Callionymus spp., while hake, saithe and whiting seemed to prefer clupeoids; hake also selectively fed on argentine and blue whiting to some degree. In summary, this previous analysis provided evidence of interannual changes in prey importance and also the existence of strong prey preferences in certain predators.

Given that density-dependent prey consumption was identified on an annual basis for certain predators, similar density-dependent predation patterns would 
be expected to occur in space or within years. If, however, strong prey preferences exist, as our previous study (Pinnegar et al. 2003) suggested for certain predators, stomach contents at a given point in space and time would be expected to be not or only slightly related to prey availability at the same scale. There are at least 2 reasons for this prediction not to hold true: non-random stomach sampling and aggregative predator response. The definition of the standard forage ratio used for determining prey preferences implicitly assumes that the spatial distribution of the predator is independent of that of the prey. If this condition is not satisfied, as in the case of aggregative response or as a result of non-random stomach sampling, spurious estimates of prey preferences might result. In the present study we first investigated the spatial and seasonal patterns of prey occurrence in predator stomachs in the Celtic Sea. We applied the same approach to determine the spatial patterns of prey abundance in the environment using bottom trawl survey data and then compared the two. We then examined the aggregative response, trying to establish if links exist between the spatial distribution of predators and preys in the environment.

In addition to the investigated prey species/families, all predators consume a wide range of other prey species (see Table 1). Cannibalism, found to be important for cod in the Barents Sea (Bogstad et al. 1994), on Georges Bank (Tsou \& Collie 2001) and on the northeast US shelf (Link \& Garrison 2002), is nearly absent from the Celtic Sea. Few predator stomachs of notorious cannibalistic species such as cod $(0 \%)$ or hake $(<1 \%)$ have been found to contain eggs and larvae of their own species (Trenkel et al. 2004a).

\section{MATERIALS AND METHODS}

Stomach-content data. Between 1977 and 1994, UK and French researchers collected stomachs from fish in the Celtic Sea (Fig. 1). UK samples were taken as part of annual research cruises. Date, location, predator length, stomach fullness (on a 10-point scale), prey identity, prey number and digestion state (on a 4-point scale), were recorded along with the number of empty stomachs. Where discernible, prey length was also recorded.

French samples were collected aboard commercial trawlers during routine fishing operations in the Celtic Sea. These data have been largely documented (du Buit 1982, 1995, 1996, du Buit \& Merlinat 1987) but not in the context of spatial and temporal consumption patterns. ICES subdivision, predator length, prey identity, prey number, prey weight (g), and digestion state (on a 5 -point scale) were recorded. No data were available relating to non-identifiable prey remains or empty stomachs. As no precise location information was available for this data set, the latitude and longitude at the centre of each ICES subdivision was used. For further description of all data, see Pinnegar et al. (2003).

Overall, stomach sampling was very uneven across predator species (Table 1). To balance the data, stomachs from predators $<20$ and $>100 \mathrm{~cm}$, depths $<40$ and $>300 \mathrm{~m}$ and latitudes $<47.12$ and $>52.12^{\circ} \mathrm{N}$ were removed from the analysis.

Survey indices. Density estimates per haul for all fish prey species from the annual ground-fish survey of CEFAS (Centre for Environment, Fisheries \& Aquaculture Science) were used for the period 1982 to 1994 to match the stomach data. Samples were collected in spring (March/April) each year and, for the period 1982 to 1988, also in autumn (November and December), using a Portuguese high headline trawl (PHHT), hauled by the RV 'Cirolana'. The distance travelled by the vessel whilst hauling, together with the horizontal opening of the net, were used to calculate 'swept area' and consequently fish numbers per unit area per haul (see Trenkel et al. 2004b). No corrections for catchability differences were attempted. In addition to abundance, geographic position and depth of the hauls were also used.

Preliminary analysis. Some fish species or individuals of a particular size are prone to regurgitating their stomach contents when being hauled on board (e.g. Staniland et al. 2001). Consequently, prey presence in stomachs might not always provide an accurate impression of prey-consumption patterns in the wild. For the UK data, all empty and regurgitated stomachs were classified together as empty while for the French data only full stomachs were recorded. Over $84 \%$ of (UK) predator stomachs contained food, with the notable exception of megrim, for which a large majority $(64 \%)$ of stomachs were empty or regurgitated. The UK data were used to study the impact of depth, latitude and predator length on the probability of a stomach being non-empty using generalised additive models (GAM, binomial error distribution and log-link function). The probability of a predator stomach containing any food (fish or other) was stable between years for all species except megrim. Latitude was significant for hake $(p=0.0001)$ and whiting $(p=0.0002)$, while depth was significant for megrim $(\mathrm{p}<0.0001)$ and again whiting $(p=0.0001)$. When looking at the smooth functions for these significant explanatory variables, the only clear pattern was for megrim, where an increase in empty stomachs occurred with increasing sampling depth (Fig. 2). All other significant relationships were more likely to be a result of noise created by the unbalanced sampling design (data not shown). In the subsequent analysis we assumed that the same patterns also applied to the French data. 


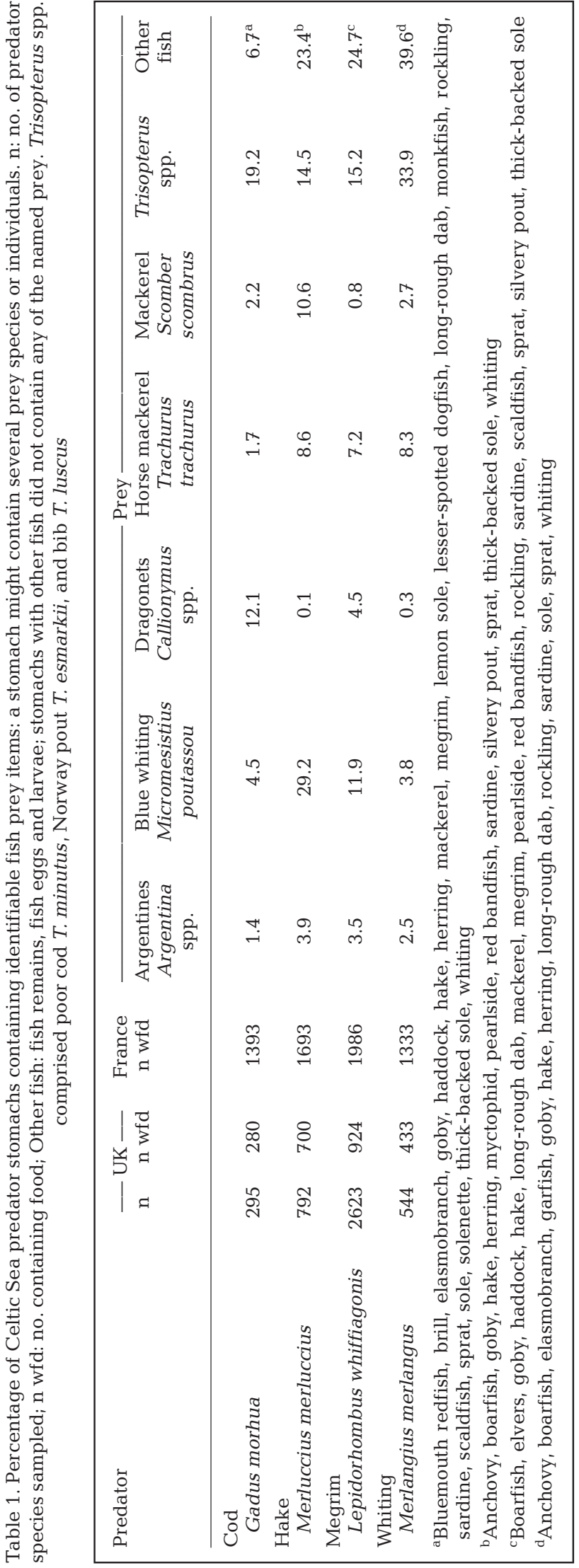

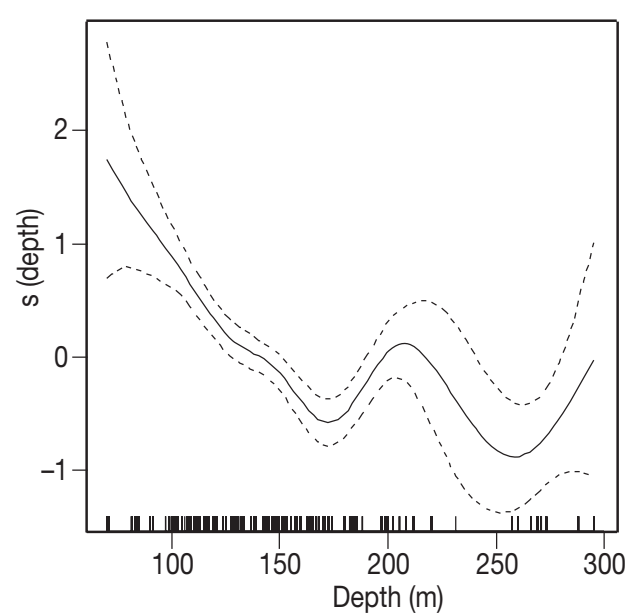

Fig. 2. Lepidorhombus whiffiagonis. Probability of megrim stomach containing food as a smooth function of depth. Whiskers inside abscissas indicate data availability

Spatial and temporal prey consumption. For studying spatial and seasonal patterns of prey occurrence in predator stomachs, a presence-absence variable was created by coding a predator stomach containing a given prey species as 1, independent of how many individuals of the relevant species were present. Initial analyses suggested that very few stomachs had more than 1 identifiable fish-prey item, hence justifying a presence-absence analysis. All stomachs containing food, whether fish or other, were coded as 0 . The presence-absence variables were then analysed using GAM. Spatial effects were modelled by including latitude and depth as separate explanatory variables, since in the Celtic Sea depth is correlated with longitude (Fig. 1). Seasonal effects were modelled by including sampling month as a continuous variable. In order to remove confounding effects due to variable predator length and interannual variability, these were also included in the analysis. To increase sample size, the stomachs of all predators were analysed together for a given prey species but allowing for separate spatial (latitude and depth) and seasonal (month) relationships for each species and adding a factor for species. A common (species-independent) relationship was assumed for predator length, as the selected predators have similar prey selection strategies (Pinnegar et al. 2003). The fitted model was then:

$$
\begin{aligned}
& \ln (p)=\text { species }+ \text { year }+ \text { length } \\
& +s \text { (month) }+s_{i}\left(\text { month }_{i}\right)+s \text { (lat) } \\
& +S_{i}\left(\text { lat }_{i}\right)+s(\text { depth })+S_{i}\left(\text { depth }_{i}\right)
\end{aligned}
$$

where $p$ is the probability of a stomach containing a given prey; $s()$ indicates a common smooth function (regression spline) for all species and $s_{i}()$ a separate function for Species $i$. In order to test whether different variables were significant and, in addition, whether the smooth functions were significantly different for 
each species, each smooth term was fitted to all species together-term $s()$ - as well as to each species independently - terms $s_{i}\left(\right.$ ). If the functional relationship $s_{i}()$ for a species was significantly different from the average relationship $s($ ), this species was separated when fitting the average relationship in a second step. For example, if for hake the seasonal pattern was different compared to that of all species combined, in the final model the term $s_{\text {not hake }}\left(\right.$ month $\left._{\text {not hake }}\right)+s_{\text {hake }}\left(\right.$ month $\left._{\text {hake }}\right)$ would replace all terms involving month in Eq. (1).

Model fitting (binomial error distribution and log-link function) and automatic selection of the degrees of freedom for the penalised regression splines, were performed using the generalised cross-validation method based on minimising the jackknifed squared prediction error in the mgcv package in $\mathrm{R}$ ( $\mathrm{R}$ development Core Team 2003) as described in Wood \& Augustin (2002).

Despite restricting the stomachs used in the analysis, the sampling design remained unbalanced, mainly with respect to month. Due to a lack of spatially and temporally resolved stomachs containing Argentina spp. and Callionymus spp., this analysis was only carried out for the prey blue whiting, mackerel, horse mackerel and Trisopterus spp. and relevant predators.

Multivariate diet analysis. Multiple correspondence analysis (MCA) was used to investigate the general relationship between the presence of the 4 prey species in predator stomachs and environmental covariates transformed into factors (excluding year effects) for each of the 4 predators. MCA ordination allows investigation and visualisation of multiple correlations between nominal variables (factors). Based on the GAM analysis, 2 seasons were defined; summer running from April to September and winter for the months October to March. Latitude had 3 levels, low $\left(<49^{\circ} \mathrm{N}\right)$, medium $\left(49\right.$ to $\left.51^{\circ} \mathrm{N}\right)$ and high $\left(>51^{\circ} \mathrm{N}\right)$, and depth was divided into shelf (>150 $\mathrm{m}$ ) and slope $(<150 \mathrm{~m})$. We considered 3 predator length categories: small $(<40 \mathrm{~cm})$, medium $(40$ to $60 \mathrm{~cm})$ and large $(>60 \mathrm{~cm})$. Prey species composition was coded, such that 1 or several prey species were present, i.e. combinations of 1, 2 or 3 species. All 4 prey species were never present at the same time. Prey species other than those investigated in this study were grouped as 'other'.

Spatial prey distribution. GAM were fitted to the survey density estimates including zero hauls (negative binomial error distribution and log-link function). Inspection of residual plots revealed that there remained a mean-variance problem which could be overcome by raising the survey densities $D$ to the power 0.2. Year and season (spring or autumn survey) as well as their interaction were fitted as factors. Explanatory variables modelled as non-parametric smooth functions were latitude and depth, and separate patterns in spring $(j=1)$ and autumn $(j=2)$ were tested. The model is then:

$$
\begin{aligned}
D^{0.2}= & \text { year } \times \text { season }_{j}+s(\text { lat })+s_{j}\left(\text { lat }_{j}\right) \\
& +s(\text { depth })+s_{j}\left(\text { depth }_{j}\right)
\end{aligned}
$$

Year $\times$ season $_{j}$ indicates that the main effects as well as the interaction term were fitted. As before, $s()$ indicates the average smooth function for both seasons and $s_{j}($ ) the deviations from this for each season. First the full model (Eq. 2) was fitted; the final model then only consists of the significant terms. Each prey species was analysed separately.

Aggregative response. For each predator-prey couple a GAM was fitted to the density estimates by haul in order to explain the local predator density by the prey density. Survey density-estimates per haul were normalised $\left(D^{*}\right)$ for each season, year and species (predators and prey) separately to allow comparisons across survey years and seasons. The fitted model was

$$
\ln \left(D_{\text {predator }}{ }^{*}+0.001\right)=s\left(D_{\text {prey }^{*}}{ }^{*}\right)
$$

For all predators the normalised density was calculated only for length groups for which the proportion of fishes in the diet was stable (see Pinnegar et al. 2003). These minimum lengths were $50 \mathrm{~cm}$ for cod, $35 \mathrm{~cm}$ for hake, $25 \mathrm{~cm}$ for megrim and $20 \mathrm{~cm}$ for whiting.

Spatial co-occurrence. The spatial co-occurrence of predator and prey species was described using the local index of collocation (LIC) proposed by Bez \& Rivoirard (2000). This index assumes a value of 1 if the densities of 2 species are proportional to each other in all measured locations (hauls) and zero if they never occur together. It is defined as:

$$
\operatorname{LIC}(t)=\frac{\sum_{i=1}^{n} \hat{D}_{i}^{\text {prey }}(t) \hat{D}_{i}^{\text {predator }}(t)}{\sqrt{\sum_{i=1}^{n}\left(\hat{D}_{i}^{\text {prey }}(t)\right)^{2} \sum_{i=1}^{n}\left(\hat{D}_{i}^{\text {predator }}(t)\right)^{2}}}
$$

where $\hat{D}_{i}^{\text {prey }}(t)$ is the survey density estimate for a given prey in Haul $i$ in Year $t$. The significance of the observed LIC values was tested with a permutation test. For this the predator survey density was 'permuted' between sampling stations while the prey density was kept fixed. The LICs calculated from the pairs of 'permuted' predator density and original prey density provided the empirical distribution of the LIC from which the probability of the observed LIC was derived. The tests were carried out for each survey (spring and autumn), year and predator-prey couple separately.

\section{RESULTS}

\section{Spatial and temporal prey consumption}

Examination of stomach-contents data for the 4 predators yielded many significant relationships and coherent patterns on a seasonal and a temporal basis (Table 2). In terms of seasonality, consumption patterns 
Table 2. Factors significantly affecting probability of a prey species being present in predator stomachs. Predator name is given if pattern is significantly different; $\mathrm{c}$ : cod; h: hake; m: megrim; w: whiting. Results from generalised additive models with variables as smooth functions. ${ }^{* *} p<0.001$. Specific names in Table 1

\begin{tabular}{|c|c|c|c|c|c|c|}
\hline Prey species & $\begin{array}{c}\% \text { stomachs } \\
\text { with species }\end{array}$ & $\%$ deviance & $\begin{array}{l}\text { Predator species } \\
\text { in model }\end{array}$ & Month & Latitude & Depth \\
\hline Blue whiting & 11.4 & 52 & $\mathrm{c}, \mathrm{h}, \mathrm{m}, \mathrm{w}$ & Megrim $^{* *}$, others ${ }^{* *}$ & All ${ }^{* *}$ & Hake $^{* *}$, others ${ }^{* *}$ \\
\hline Horse mackerel & 10.1 & 39 & $\mathrm{~h}, \mathrm{~m}, \mathrm{w}$ & $\mathrm{All}^{* *}$ & Hake $^{* *}$, others ${ }^{* *}$ & $\mathrm{All}^{* *}$ \\
\hline Mackerel & 11.9 & 32 & $\mathrm{~h}, \mathrm{w}$ & All ${ }^{* *}$ & Hake** & Whiting $^{* *}$, hake ${ }^{* *}$ \\
\hline Trisopterus spp. & 19.3 & 21 & $\mathrm{c}, \mathrm{h}, \mathrm{m}, \mathrm{w}$ & Megrim $^{* *}$ & ns & Hake $^{* *}$, others ${ }^{* *}$ \\
\hline
\end{tabular}
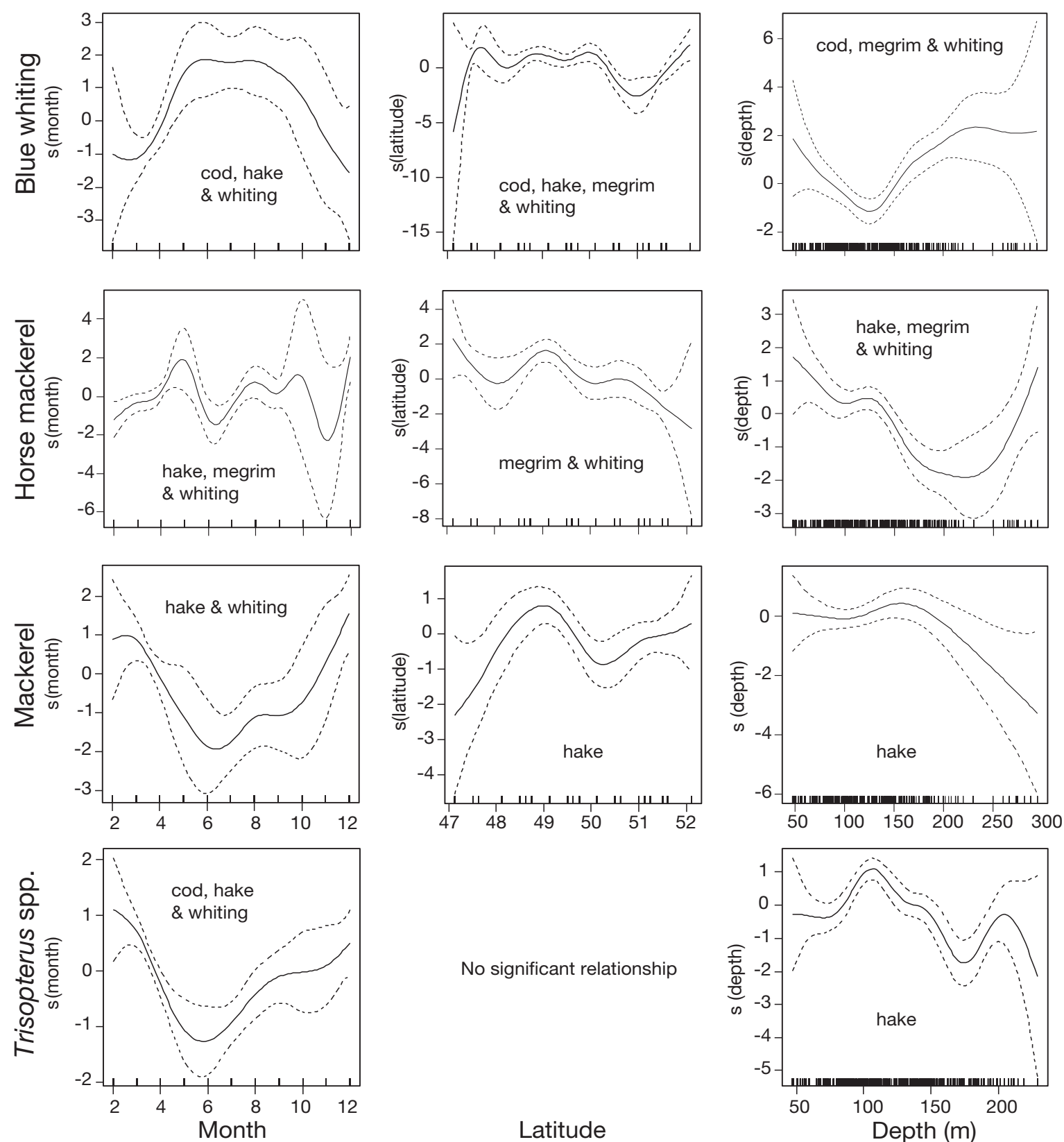

No significant relationship

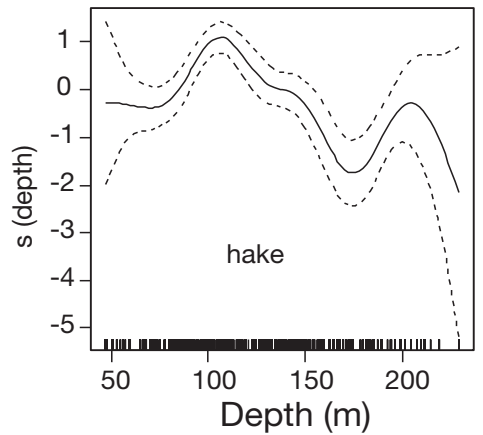

Fig. 3. Probability of predator stomach containing given prey species as a function of month, latitude and depth. Whiskers inside abscissas indicate data availability. Specific names in Table 1 
for whiting and hake were broadly similar across all 4 prey species considered (Fig. 3: left-hand graphs). Cod exhibited the same broad patterns as hake and whiting for blue whiting and Trisopterus spp., but not for mackerel and horse mackerel. Blue whiting was consumed more often during the summer months by all 4 preda-
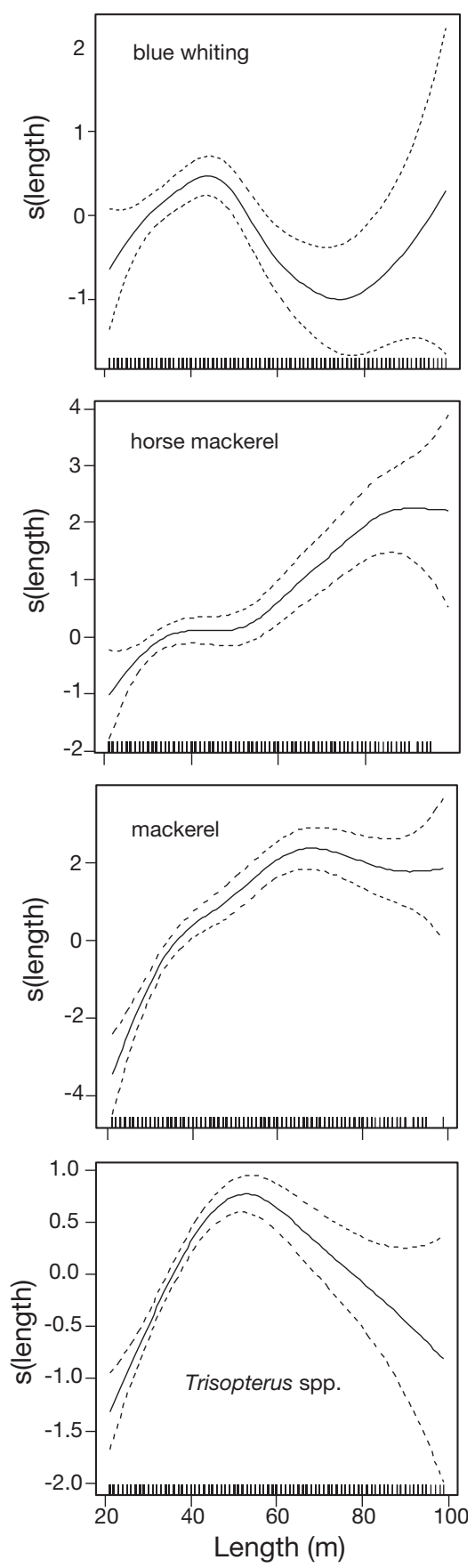

Fig. 4. Probability of predator stomach containing given prey as a function of predator length (independent of species) (general additive model, GAM, binomial error distribution, log-link function). Whiskers inside abscissas indicate data availability. Specific names in Table 1 tors. Mackerel and Trisopterus spp. were found more often in predator stomachs during the winter period, with particularly low occurrence in June. The decrease in summer was less pronounced for megrim feeding on Trisopterus spp. (result not shown). Horse mackerel was the only prey species consumed with no clear seasonal trend by hake, megrim or whiting.

Megrim and whiting exhibited a slight change in preference for horse mackerel with decreasing latitude (Fig. 3: middle graphs). Blue whiting appeared more often in predator stomachs at depths deeper than $\sim 150 \mathrm{~m}$ (>200 $\mathrm{m}$ for hake). The opposite was true for horse mackerel, mackerel and Trisopterus spp. (Fig. 3: right-hand graphs).

In terms of predator size, blue whiting was consumed more often by smaller predators $(<50 \mathrm{~cm})$, while horse mackerel and mackerel were found more often in stomachs of larger predators (>50 cm) (Fig. 4). Trisopterus spp. seemed to be consumed by predators of intermediate size $(\sim 50$ to $60 \mathrm{~cm})$. The fact that the confidence bands of the estimated non-parametric functions were tight indicated that the relationships were similar for all 4 predator species considered (see Table 2 for predators of each prey).

\section{Multivariate diet analysis}

The first 2 axes of the MCA ordinations accounted for 28 to $32 \%$ of the total variation in the diet of the 4 predators and environmental factors (Table 3). Multiple correlations of the first 2 axes ranged from 0.5 to 0.7 . Biplots of predator diets showed that for cod, blue whiting and horse mackerel, presence in stomachs and slope and low latitude habitat were associated, but also other prey, medium-sized predators and shelf habitat. Similarly Trisopterus spp. and summer were closely correlated (Fig. 5).

For hake, blue whiting presence was again related to slope habitat but also to medium predator size and low latitude. Horse mackerel consumption, summer and large predator size were correlated. Small predators were correlated with other prey species, with winter and with medium latitude.

Table 3. Multiple correspondence analysis (MCA) of correlations between prey presence in predator stomachs and environmental factors. Specific names in Table 1

\begin{tabular}{|lcccr|}
\hline \multirow{2}{*}{ Species } & \multicolumn{2}{c}{ Correlations } & \multicolumn{2}{c|}{ \% variance } \\
& Axis 1 & Axis 2 & Axis 1 & 1 \& 2 \\
\hline Cod & 0.612 & 0.519 & 15.31 & 28.29 \\
Hake & 0.665 & 0.605 & 16.63 & 31.75 \\
Megrim & 0.639 & 0.568 & 15.98 & 30.18 \\
Whiting & 0.609 & 0.533 & 15.24 & 28.56 \\
\hline
\end{tabular}



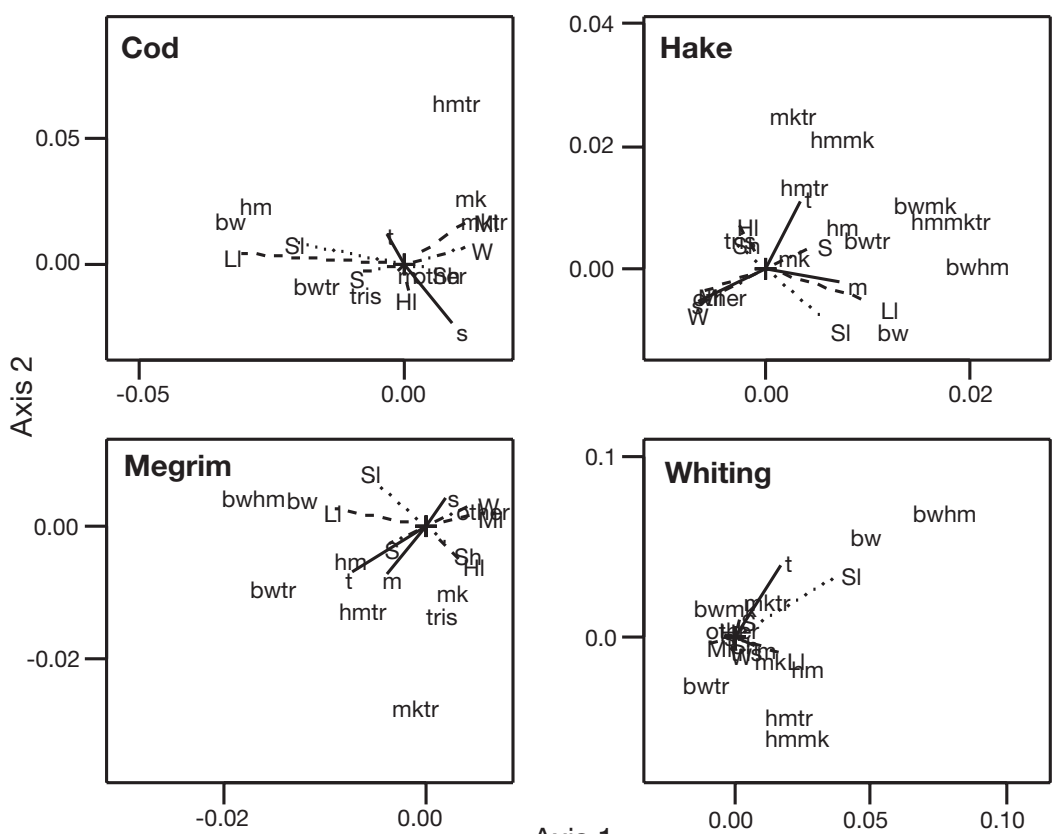

Axis 1

Fig. 5. Multiple correspondence analysis (MCA) biplots of predator diets. Points indicate scores of prey categories and environmental factors in ordination space. bw: blue whiting; hm: horse mackerel; mk: mackerel; tris: Trisopterus spp. $\mathrm{Hl}, \mathrm{Ml}, \mathrm{Ll}$ : high, medium, low latitude, respectively. Area: Sl: continental slope, Sh: continental shelf. s, m, t: small, medium and large predator size, respectively. S: summer, W: winter. Specific names in Table 1
For horse mackerel, a decreasing density with increasing latitude was observed; the pattern was identical in spring and in autumn. Horse mackerel density seemed to be higher at around 50 to $100 \mathrm{~m}$ depth in autumn and at $>200 \mathrm{~m}$ depth in spring. No significant difference was observed in average horse mackerel density between seasons $(\mathrm{p}=0.9)$.

A weak latitudinal pattern was observed for mackerel in spring but not in autumn, while depth preferences resembled those of horse mackerel (i.e. high densities between 50 and $100 \mathrm{~m}$ depth in autumn), but with a stronger decrease at deeper depths (>200 m) in spring. Average mackerel densities were significantly lower in autumn than in spring $(\mathrm{p}=5.5 \mathrm{e}-08)$.

Trisopterus spp. density patterns were distinct from those of the other 3 prey species. Densities decreased at intermediate latitudes $\left(49\right.$ to $\left.51^{\circ} \mathrm{N}\right)$ in spring and autumn. As depth increased, fewer Trisopterus spp. were found in both seasons. The average Trisopterus spp. density was similar in both spring and autumn $(\mathrm{p}=0.96)$.

\section{Aggregative response}

For megrim, horse mackerel was related to summer consumption was weakly related to slope habitat and low latitude. Small predators were correlated with other prey species and winter, but also with medium latitude. Trisopterus spp. and mackerel were related to each other, but also high latitude and shelf.

For whiting, blue whiting consumptions was closely correlated with the slope habitat. No other strong relationships appeared.

Thus the dominant patterns were the relationships between blue whiting consumption and the slope habitat and between other prey and small-sized predators - with the exception of cod, for which the relationship was with 'medium-sized' individuals.

\section{Spatial prey distribution}

Significant latitudinal and depth-related patterns of prey density were identified for most species (Table 4, Fig. 6). Blue whiting densities did not vary significantly with latitude in spring or in autumn (data not shown), but increased with depth at both times of year. There was no overall significant difference between densities in spring and in autumn $(\mathrm{p}=0.8)$.
Significant positive relationships between the density of the predator and a particular prey were observed only for cod and whiting with Trisopterus spp., in spring (cod: $p=0.00053$; whiting: $p=0.00013$ ) and whiting with Trisopterus spp. in autumn $(\mathrm{p}=0.0014)$.

Table 4. Factors affecting abundance of a prey species in scientific groundfish surveys. Generalised additive models (negative binomial error function with $\log -\operatorname{link}$; abundance to power of 0.2 ) with season (spring or autumn) and year as a factor and latitude and depth as smooth functions (either per survey or together); $\mathrm{n}=815,12 \mathrm{yr}$ in spring, $7 \mathrm{yr}$ in autumn. ${ }^{* *} \mathrm{p}<0.001$. Both $=$ spring and autumn patterns did not differ; spring, autumn = distinct pattern for that period. Specific names in Table 1

\begin{tabular}{|lcccl|}
\hline $\begin{array}{l}\text { Prey species } \\
\text { Blue whiting }\end{array}$ & 42 & 0.80 & Spring $^{* *}$ & $\begin{array}{l}\text { Spring } \\
\text { Autumn }\end{array}$ \\
Horse mackerel & 38 & 0.9 & Both $^{* *}$ & $\begin{array}{l}\text { Spring } \\
\text { Autumn }\end{array}$ \\
Mackerel & 36 & $* *$ & Spring $^{* *}$ & $\begin{array}{l}\text { Spring } \\
\text { Autumn }\end{array}$ \\
Trisopterus spp. & 33 & $* *$ & $\begin{array}{l}\text { Spring** } \\
\text { Autumn** }\end{array}$ \\
\hline
\end{tabular}




\section{Spatial co-occurrence}

The LIC suggested that whiting had high cooccurrence with dragonets Callionymus spp. and Trisopterus spp. both in spring and in autumn; this index was significant in most years (Table 5). For Trisopterus spp. this supports the notion of a strong aggregative response, as implied in preceding subsection. No significant relationships were observed for any other predator-prey couple.

\section{DISCUSSION}

The most important finding of this study is that hake, cod and whiting in the Celtic Sea appear to exhibit spatial and seasonal prey-switching behaviour. When studying the diet of whiting and haddock in the Moray Firth (NE Scotland), Greenstreet et al. (1998) also found indications of seasonal shifts in feeding patterns. Sandeel were more prominent in whiting diets during the summer, which coincided with their peak abun-
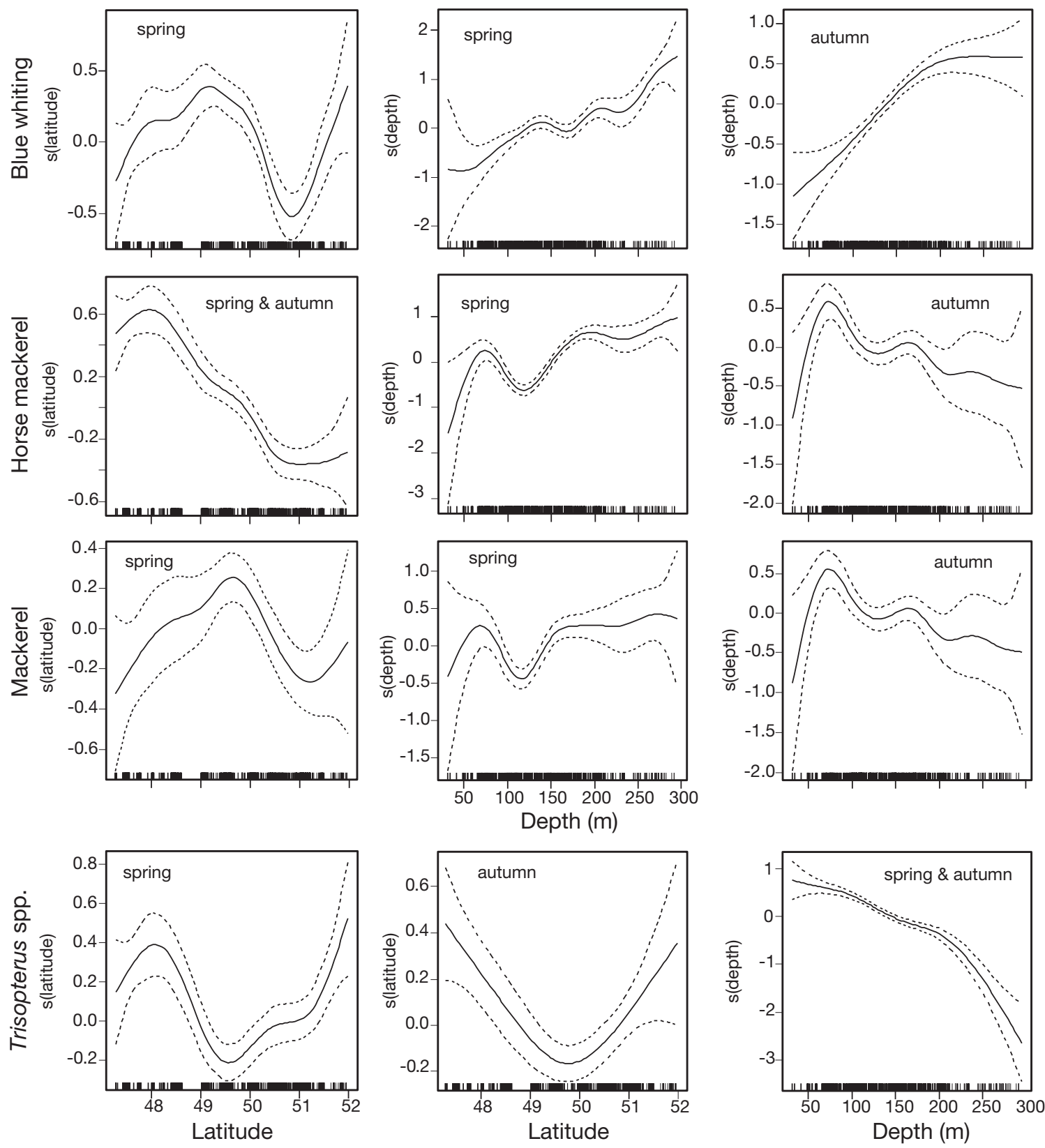

Fig. 6. Non-linear relationships between swept-area survey density-estimates as a function of latitude and depth (GAM, negative binomial error distribution, log-link function) in spring and autumn. Whiskers inside abscissa indicate availability of data. 
Table 5. Average annual local index of collocation for predators and prey based on swept-area density estimates. Predator density estimates are for fish bigger than minimum length: cod $>50 \mathrm{~cm}$; hake $>35 \mathrm{~cm}$; megrim $>25 \mathrm{~cm}$; saithe $>40 \mathrm{~cm}$; whiting $>20 \mathrm{~cm}$. ${ }^{*} 50$ to $75 \%$ of years with p-value $<0.05$; ${ }^{* *}>75 \%$ of years with $\mathrm{p}$-value $<0.05$. Specific names in Table 1

\begin{tabular}{|lcccc|}
\hline \multirow{2}{*}{ Prey } & \multicolumn{4}{c|}{ Predator } \\
\cline { 2 - 5 } & Cod & Hake & Megrim & Whiting \\
\hline Spring (12 yr) & & & & \\
$\quad$ Argentines & 0.34 & 0.29 & 0.38 & 0.16 \\
Blue whiting & 0.07 & 0.31 & 0.24 & 0.03 \\
Dragonets & 0.24 & 0.12 & 0.13 & $0.40^{*}$ \\
Horse mackerel & 0.04 & 0.17 & 0.29 & 0.11 \\
Mackerel & 0.16 & 0.22 & 0.25 & 0.14 \\
Trisopterus spp. & 0.32 & 0.18 & 0.16 & $0.51^{*}$ \\
Autumn (7 yr) & & & & \\
Argentines & 0.25 & 0.28 & 0.42 & 0.07 \\
Blue whiting & 0.12 & 0.19 & 0.40 & 0.07 \\
Dragonets & 0.15 & 0.20 & 0.33 & $0.35^{*}$ \\
Horse mackerel & 0.02 & 0.07 & 0.12 & 0.17 \\
Mackerel & 0.04 & 0.05 & 0.06 & 0.28 \\
Trisopterus spp. & 0.29 & 0.19 & 0.01 & $0.59^{* *}$ \\
\hline
\end{tabular}

dance, while clupeids and gadoids were more important at other times.

The timing of the surveys in the Celtic Sea does not allow us to assess whether prey densities are different in summer and winter. However, the fact that average densities in spring and autumn were different for mackerel and Trisopterus spp. might indicate densitydependent feeding behaviour throughout the year, at least on these species. For blue whiting no such seasonal difference was observed; however, it should be remembered that densities were estimated from bottomtrawl data which might not adequately reflect the abundance of pelagic species such as blue whiting (although the survey was originally designed to monitor mackerel: see Trenkel et al. 2003). For hake, the suggestion of density-related prey selection is supported by our previous analyses (Pinnegar et al. 2003). However, for whiting no such effects had been identified previously. It seems likely that for whiting, aggregated predator-prey patterns have been affected by non-random stomach sampling. We will come back to this point when discussing the results of the aggregative-response investigations.

The higher predation on blue whiting during the summer might be due to the arrival of juveniles in the Celtic Sea during this period. Most blue whiting in hake stomachs were around $20 \mathrm{~cm}$. This corresponds to Age 2 (2 yr). Blue whiting spawn during February to March on the Porcupine bank to the NW of the Celtic Sea at depths of around $400 \mathrm{~m}$ (Pawson 1979). After spawning the majority of adults move northwards, but some larvae or juveniles move south as far as the Bay of Biscay and Celtic Sea, where they are typically found at depths from $~ 200 \mathrm{~m}$ downwards (Carrera et al. 2001).

Similarly, the life cycle of mackerel might also be responsible for their reduced consumption during the summer. The central Celtic Sea is a major spawning area for mackerel (March to June). In late summer, juvenile mackerel move to coastal areas and only return to the central Celtic Sea in autumn (Quéro 1984). The mackerel found in our predator stomachs were around 15 to $20 \mathrm{~cm}$ long, which corresponds to 1 to 2 yr-old individuals.

The 2 dominant Trisopterus species (T. minutus and T. esmakii) in the Celtic Sea are often caught in the same hauls, although their distribution patterns are subtly different (Warnes \& Jones 1995). Poor cod ( $T$. minutus) occur over the whole of the survey area, but the greatest densities are found in the shallow areas around Cornwall and in the western English Channel. Their abundance is highly variable and high densities may often be recorded. The distribution of poor cod is, to some extent, complementary to that of Norway pout (T. esmarkii), which is a more northerly species. In the survey area, Norway pout is most abundant in the northern Celtic Sea and its distribution does not extend into the southern part or into deeper waters. Abundances in the autumn surveys have tended to be greater than in the spring surveys (Warnes \& Jones 1995). This might explain why Trisopterus spp. were consumed less often during the summer than in winter.

The absence of seasonal predation patterns on horse mackerel might reflect the fact that this species appears to be present in the Celtic Sea all year round, although in spring and summer some adults migrate north and eastwards into the North Sea.

Depth-related increases in blue whiting consumption were identified for all 4 predators. This observation agreed with the bathymetric distribution of this species, which tends to occur at higher densities only in the deeper waters of the shelf-edge. Conversely, population densities of horse mackerel, mackerel and Trisopterus spp. were higher in the shallower waters of the continental shelf, and this seemed to coincide with density-dependent predation by their respective predators.

When analysing the UK stomach data, megrim stomachs were found to be less likely to contain food if they came from greater depths. For hake, du Buit (1996) described a depth-effect, but none could be identified from the present analyses. Johansen (2002) reported that for cod in the Barents Sea, the proportion of empty stomachs decreased with increasing body length up to $\sim 40 \mathrm{~cm}$. The absence of such patterns for cod in the present study might be due to the fact that stomachs were mainly available for larger predators only, with very few stomachs sampled for smaller individuals. 
Body size plays an important role in determining which items are suitable for consumption by a particular predator (Pinnegar et al. 2003). Blue whiting and Trisopterus spp. were primarily consumed by smaller predator individuals, while horse mackerel and mackerel were found in stomachs of larger predators. The smallest mackerel found in the Celtic Sea stomach data were $\sim 15 \mathrm{~cm}$. As potential swimming speed increases with increasing body size (He 1993), it is perhaps not surprising that only larger predators were able to catch mackerel.

Given that Callionymus spp. was found in $<1 \%$ of all whiting stomach samples, the significant relationship between Callionymus spp. and whiting distributions seems likely to be due to a common habitat preference rather than any indication of an active aggregative response. In contrast, there could be strong evidence for an aggregative response by whiting on Trisopterus spp., since their spatial distributions were closely matched, and Trisopterus spp. appeared in over onethird of all whiting stomach samples. As an aggregative response is expected to lead to strong prey preferences and none had been found at the aggregate level, standardised forage-ratio estimates for whiting may have been biased by non-random stomach sampling. Indeed, Temming et al. (2004) also suggested an aggregative response involving whiting preying on sandeel in the North Sea. Thus, it seems that in the Celtic Sea Trisopterus spp. may play a similar role for whiting as sandeel does in the North Sea. Sandeel and Trisopterus spp. have very different catchabilities, since sandeels burrow into the sediment whereas Trisopterus species live in the water column. A direct consequence of the aggregative response of whiting on Trisopterus spp. might be that a disproportionately large number of the latter will be caught and discarded by trawler fleets targeting whiting (Rochet et al. 2002).

No evidence was found for an aggregative response involving hake feeding on blue whiting or Argentina spp., nor an aggregative response involving cod and megrim preying on dragonets Callionymus spp., even though standardised forage ratios had suggested significant prey preferences (Pinnegar et al. 2003). A lack of evidence for aggregative response on pelagic prey such as blue whiting or horse mackerel might indicate insufficient spatial and temporal resolution in the available trawl survey data or problems related to nonrandom spatial and temporal stomach samples. As an alternative explanation, most feeding by piscivorous species, including cod, is known to occur at particular times during the day (notably dawn and dusk: Jarre et al. 1991) that did not correspond with the time of day that stomach sampling took place in our study.

Cod, hake, megrim and whiting shared the same set of prey species in the Celtic Sea, in particular for Tris- opterus spp. (which was found in $>15 \%$ of all sampled predator stomachs), and to a lesser degree for blue whiting (4 to $29 \%$ of stomachs) (see Table 1). However, this diet overlap was heterogeneous in both space and time and involved different predator size classes. Furthermore, as prey resources did not seem to be limiting at any point in time or space, the observed dietary overlap does not imply that competition between predators occurred.

Acknowledgements. This work was funded by the European Community under Framework V, project contract QLRT1999-01609 (Development of Structurally Detailed Statistically Testable models of marine populations, $\mathrm{DST}^{2}$ ), and the UK Department for Environment, Food \& Rural Affairs contract MF0322.

\section{LITERATURE CITED}

Anderson TW (2001) Predator responses, prey refuges, and density-dependent mortality of a marine fish. Ecology 82: 245-257

Bez N, Rivoirard J (2000) Indices of collocation between populations. In: Checkley DM, Hunter JR, Motos L, van der Lingen CD (eds) Report of a workshop on the use of continuous underway fish egg sampler (CUFES) for mapping spawning habitat of pelagic fish. GLOBEC Rep 14:1-65

Bogstad B, Lilly GR, Mehl S, Palsson OK, Stefansson G (1994) Cannibalism and year-class strength in Atlantic cod (Gadus morhua L.) in Arcto-boreal ecosystems (Barents Sea, Iceland, and eastern Newfoundland). ICES Mar Sci Symp 198:576-599

Carrera P, Meixide M, Porteiro C, Miquel J (2001) Study of blue whiting movements around the Bay of Biscay using acoustic methods. Fish Res 50:151-161

de Panafieu JB (1986) Alimentation hivernale des différents stocks de merlans (Merlangius merlangus L.) en Mer du Nord. Cybium 10:231-248

Drossel B, Mckane AJ, Quince C (2004) The impact of nonlinear functional responses on the long-term evolution of food web structure. J Theor Biol 229:539-548

du Buit MH (1982) Essai d'évaluation de la prédation de quelques téléostéens en Mer Celtique. J Cons Int Explor Mer 40:37-46

du Buit MH (1995) Food and feeding of cod (Gadus morhua L.) in the Celtic Sea. Fish Res 22:227-241

du Buit MH (1996) Diet of hake (Merluccius merluccius) in the Celtic Sea. Fish Res 28:381-394

du Buit MH, Merlinat F (1987) Alimentation du merlan Merlangius merlangus L. en Mer Celtique. Rev Trav Inst Pêches Marit 49:5-12

Garrison LP, Link JS (2000) Dietary guild structure of the fish community in the northeast United States continental shelf ecosystem. Mar Ecol Prog Ser 202:231-240

Greenstreet SPR, McMillan JA, Armstrong E (1998) Seasonal variations in the importance of pelagic fish in the diet of piscivorous fish in the Moray Firth, NE Scotland: a response to variation in prey abundance? ICES J Mar Sci 55:121-133

Hassell MP, May RM (1974) Aggregation of predators and insect parasites and its effect on stability. J Anim Ecol 43: 567-594

He P (1993) Swimming speeds of marine fish in relation to fishing gears. ICES Mar Sci Symp 196:183-189 
Jarre A, Palomares ML, Soriano ML, Sambilay VC, Pauly D (1991) Some new analytical and comparative methods for estimating the food consumption of fish. ICES Mar Sci Symp 193:178-184

Jennings S, Kaiser MJ (1998) The effects of fishing on marine ecosystems. In: Blaxter JHS, Southward AJ, Tyler PA (eds) Advances in marine biology, Vol 34. Academic Press, San Diego, CA, p 201-352

Johansen GO (2002) Temporal and spatial variation in predation on juvenile herring (Clupea harengus L.) by Northeast Arctic cod (Gadus morhua L.) in the Barents Sea in 1984-1997. ICES J Mar Sci 59:270-292

Link JS (2002) Does food web theory work for marine ecosystems? Mar Ecol Prog Ser 230:1-9

Link JS, Garrison LP (2002) Trophic ecology of Atlantic cod Gadus morhua on the northeast US continental shelf. Mar Ecol Prog Ser 227:109-123

Murdoch WW (2002) Single-species models for many-species food webs. Nature 417:541-543

Pawson MG (1979) Blue whiting. Fish Lab Lowestoft Leaf 45

Pedersen J (1999) Diet comparison between pelagic and demersal whiting in the North Sea. J Fish Biol 55: 1096-1113

Pinnegar JK, Trenkel VM, Tidd AN, Dawson WA, du Buit MH (2003) Does diet in Celtic Sea fishes reflect prey availability? J Fish Biol 63(Suppl A):197-212

Quéro JC (1984) Les poissons de mer des pêches françaises. Grancher, Paris

Rochet MJ, Péronnet I, Trenkel VM (2002) An analysis of discards from the French trawler fleet in the Celtic Sea. ICES J Mar Sci 59:538-552

Seyhan K, Grove DJ (1998) Food consumption of whiting, Merlangius merlangus, in the Eastern Irish Sea. Fish Res 38:233-245

Editorial responsibility: Otto Kinne (Editor-in-Chief), Oldendorf/Luhe, Germany
Spencer PD, Collie JS (1995) A simple predator-prey model of exploited marine fish populations incorporating alternative prey. ICES J Mar Sci 53:615-628

Staniland IJ, Hart PJ, Bromley PJ (2001) The regurgitation of stomach contents in trawl caught whiting, evidence of a predator size effect. J Fish Biol 59:1430-1432

Stefánsson G, Pálsson OK (1997) Statistical evaluation and modelling of the stomach contents of Icelandic cod (Gadus morhua). Can J Fish Aquat 54:169-181

Temming A, Götz S, Mergardt N, Ehrich S (2004) Predation of whiting and haddock on sandeel: aggregative response, competition and diel periodicity. J Fish Biol 64:1351-1372

Trenkel VM, Pinnegar JK, Blanchard JL, Tidd AN (2004a) Can multispecies models be expected to provide better assessments for Celtic Sea groundfish stocks? ICES Annual Science Conference, Vigo. Int Counc Explor Sea Comm Meet 2004/FF:05

Trenkel VM, Pinnegar JK, Rochet MJ, Rackham B (2004b) Different survey designs provide similar pictures of community structure but not of individual fish populations. ICES J Mar Sci 61:351-362

Tsou TS, Collie JS (2001) Predation-mediated recruitment in the Georges Bank fish community. ICES J Mar Sci 58: 994-1001

Van der Meer J, Ens BJ (1997) Models of interference and their consequences for the spatial distribution of ideal and free predators. J Anim Ecol 66:846-58

Warnes S, Jones BW (1995) Species distributions from English Celtic Sea groundfish surveys, 1984 to 1991, Ministry of Agriculture, Fisheries and Food, Directorate of Fisheries Research, Lowestoft

Wood SN, Augustin NH (2002) GAMs with integrated model selection using penalized regression splines and applications to environmental modelling. Ecol Model 157:157-177

Submitted: May 10, 2004; Accepted: April 26, 2005

Proofs received from author(s): August 10, 2005 